\title{
Methane profiles from GOSAT thermal infrared spectra
}

\author{
Arno de Lange and Jochen Landgraf \\ Earth Group, SRON Netherlands Institute for Space Research, Utrecht, the Netherlands \\ Correspondence: Arno de Lange (a.de.lange@ sron.nl) \\ Received: 1 June 2017 - Discussion started: 13 June 2017 \\ Revised: 18 December 2017 - Accepted: 23 December 2017 - Published: 28 June 2018
}

\begin{abstract}
This paper discusses the retrieval of atmospheric methane profiles from the thermal infrared band of the Japanese Greenhouse Gases Observing Satellite (GOSAT) between 1210 and $1310 \mathrm{~cm}^{-1}$, using the RemoTeC analysis software. Approximately one degree of information on the vertical methane distribution is inferred from the measurements, with the main sensitivity at about $9 \mathrm{~km}$ altitude but little sensitivity to methane in the lower troposphere. For verification, we compare the GOSAT-TIR methane profile retrieval results with profiles from model fields provided by the Monitoring Atmospheric Composition and Climate (MACC) project, scaled to the total column measurements of the Total Carbon Column Observing Network (TCCON) at ground-based measurement sites. Without any radiometric corrections of GOSAT observations, differences between both data sets can be as large as $10 \%$. To mitigate these differences, we developed a correction scheme using a principal component analysis of spectral fit residuals and airborne observations of methane during the HIAPER pole-to-pole observations (HIPPO) campaign II and III. When the correction scheme is applied, the bias in the methane profile can be reduced to less than $2 \%$ over the whole altitude range with respect to MACC model methane fields. Furthermore, we show that, with this correction, the retrievals result in smooth methane fields over land and ocean crossings and no differences can be discerned between daytime and nighttime measurements. Finally, a cloud filter is developed for the nighttime and ocean measurements. This filter is rooted in the GOSAT-TIR (thermal infrared) measurements and its performance, in terms of biases, is consistent with the cloud filter based on the GOSAT-SWIR (shortwave infrared) measurements. The TIR filter shows a higher acceptance rate of observations than the SWIR filter, at the cost of a higher uncertainty in the retrieved methane profiles.
\end{abstract}

\section{Introduction}

Methane $\left(\mathrm{CH}_{4}\right)$ is, after carbon dioxide $\left(\mathrm{CO}_{2}\right)$, the strongest anthropogenic greenhouse gas, with an estimated total radiative forcing of $0.97 \mathrm{~W} \mathrm{~m}^{-2}$ for 2011 with respect to the preindustrial levels of the year 1750 (Myhre et al., 2013). The forcing per molecule is $\approx 100$ times stronger than that of carbon dioxide, but the abundance is $\approx 200$ times lower. The current relative increase with respect to pre-industrial background levels of the year 1750 is $150 \%$ for methane, as opposed to $40 \%$ for carbon dioxide. Natural methane sources are anaerobic environments where micro-organisms convert organic material into methane. Examples are wetlands including swamps, boreal marshes, and tundra, but also lakes and oceans are natural methane sources. In line with these natural processes are the cultivation of rice paddies and cattle, both anthropogenic sources. Other sources include the burning of organic material, such as biomass burning (both natural and anthropogenic), waste burning (anthropogenic), and gas losses in the fossil fuel industry (anthropogenic; Myhre et al., 2013). For climate monitoring and prediction, it is essential to measure $\mathrm{CH}_{4}$ on a global scale and information on its vertical distribution may help to disentangle signals due to methane surface emissions and long-range transport (Jacob et al., 2016; Bousserez et al., 2015).

Satellite nadir measurements of $\mathrm{CH}_{4}$ in the thermal infrared (TIR) represent an important element of a climate observing system because of the pronounced methane sensitivity of the measurements in the upper troposphere. Therefore, these measurements can aid in the decoupling of methane emissions and transport in inverse-modelling studies (Jacob et al., 2016; Bousserez et al., 2015). Currently five nadir-viewing instruments in the thermal infrared are operational on satellite platforms; Atmospheric InfraRed Sounder (AIRS), aboard Aqua, launched in 2002 (Xiong et al., 
2008; Zou et al., 2016); Tropospheric Emission Spectrometer (TES), aboard AURA, launched in 2004 (Wecht et al., 2012; Worden et al., 2012, 2015); Infrared Atmospheric Sounding Interferometer (IASI), aboard Metop-A and Metop-B, launched in respectively 2006 and 2012 (Razavi et al., 2009; Crevoisier et al., 2013; Cressot et al., 2014; Siddans et al., 2017); Thermal and Near infrared Sensor for Carbon Observation - Fourier Transform Spectrometer (TANSO-FTS) aboard the Japanese Greenhouse Gases Observing Satellite (GOSAT), launched in 2009; Cross-track Infrared Sounder (CrIS), aboard Suomi-NPP, launched in 2011 (Han et al., 2013). Furthermore, GOSAT-2, the successor of the GOSAT satellite, will also be equipped with two thermal infrared bands (together covering the same wavelength range as the one TIR band in GOSAT) and a new generation of IASI spectrometers (IASI-NG) will fly on three successive Metop-SG A satellites of the European Organisation for the Exploitation of Meterological Satellites (EUMETSAT) Polar System of Second Generation (EPS-SG) in the 2021-2040 time frame.

In many studies on methane retrievals from thermal infrared observations of the above mentioned satellites, a bias in the methane product is observed. To address this bias, different approaches have been adopted. Xiong et al. (2008) improved the AIRS $\mathrm{CH}_{4}$ validation results by tuning absorption coefficients within the radiative transfer algorithm. Worden et al. (2012) observes a discrepancy between upper and lower tropospheric methane of $\approx 4 \%$ in the case of TES observations and mentions uncertainties in temperature, calibration inaccuracies and spectroscopy errors as the main causes. A $\mathrm{CH}_{4} / \mathrm{N}_{2} \mathrm{O}$ proxy retrieval reduces this bias to $\approx 2.8 \%$ but does not fully remove it. Siddans et al. (2017) also observes a bias of $\approx 4 \%$ and scales the methane mixing ratios retrieved from IASI measurements. Furthermore, two additional scaling parameters are fitted for the mean residual of respectively nadir observations and at the outer edge of the swath, to account for variations in interfering water vapour and scan mirror errors. The resulting methane product is within $2 \%$ of HIAPER pole-to-pole observations (HIPPO) over the full altitude range. Also Crevoisier et al. (2013) applies a radiometric correction based on mean residuals in case of IASI measurements. Finally, von Clarmann et al. (2009) mentions that 8 micro-windows are carefully selected for the MIPAS limb retrievals to reduce the known high bias of $\mathrm{CH}_{4}$.

The current study focuses on the retrieval of methane profiles from GOSAT observation in the thermal infrared band $1210-1310 \mathrm{~cm}^{-1}$. Previous work by Saitoh et al. (2012) and Holl et al. (2016) presented results of GOSAT-TIR retrievals of methane, where the measurements are radiometrically corrected using the approach of Saitoh et al. (2009). Spectral residuals in GOSAT are assessed with measurements of buoys, and are subsequently accounted for in the retrievals. In these studies, the degrees of freedom for signal (DOFS) of the retrieval is significantly lower than 1. Moreover, Zou et al. (2016) compared the retrieval of methane profiles from GOSAT and AIRS thermal infrared measurements and ob- served a prevalent bias at $9 \mathrm{~km}$ altitude of about $+3 \%$ between both satellite retrievals (AIRS minus GOSAT).

In the GOSAT-TIR studies mentioned above, the retrieval results stem from the same algorithm. In this study, we use a different algorithm and apply the RemoTeC retrieval tool to analyse the GOSAT-TIR measurements with a degrees of freedom for signal $(\mathrm{DOFS}) \approx 1$ and verify the retrieval results with profiles of the Monitoring of Atmospheric Composition and Climate (MACC) project scaled to the total column measurements of the Total Carbon Column Network (TCCON) at ground-based measurements sites. To mitigate the observed significant biases, we developed a sophisticated correction scheme based on a principal component analysis of spectral residuals using HIPPO data as an estimate for the atmospheric state. Not only does this correction scheme significantly improve our validation, we also achieve the consistency of daytime and nighttime measurements as well as continuity of methane for land-sea crossings where the measurement sensitivity to methane in the lower and middle atmosphere changes substantially. It is noted that a similar correction approach, using empirical orthogonal functions, is being used within the OCO-2 Level 2 algorithm (OCO-2, 2015).

The article is structured as follows: in Sect. 2 the GOSATTIR measurements are introduced, Sect. 3 introduces the Tikhonov regularisation scheme to invert the measurements. Finally, Sect. 4 presents the bias correction scheme and its effect on the retrievals is demonstrated.

\section{GOSAT}

The Japanese satellite GOSAT was launched in 2009 and is the world's first satellite fully dedicated to the monitoring of the two most important greenhouse gases: carbon dioxide and methane. Its main instrument is the TANSO-FTS Fourier Transform spectrometer covering four wavelength bands; the oxygen A-band $\left(\approx 13000 \mathrm{~cm}^{-1}\right)$, two bands in the shortwave infrared regime $\left(\approx 5000\right.$ and $\left.\approx 6200 \mathrm{~cm}^{-1}\right)$, and a band in the thermal infrared wavelength range $(\approx 600-$ $1600 \mathrm{~cm}^{-1}$ ). The spectral resolution of the oxygen A-band is $\approx 0.5 \mathrm{~cm}^{-1}$, whereas the other three bands show a resolution of $\approx 0.27 \mathrm{~cm}^{-1}$. This study focuses only on the retrieval of methane for the TIR band, employing the spectral window $1210-1310 \mathrm{~cm}^{-1}$. TANSO-FTS has an instantaneous field of view of $\approx 10 \mathrm{~km}$ allowing for high spatial resolution measurements. The spatial sampling, conversely, is sparse with a distance between two consecutive measurements of up to several $100 \mathrm{~km}$.

Over the course of the mission, Japan Aerospace Exploration Agency (JAXA) has released several level 1B data versions, and in this study v16x160 of L1B data has been used. For the TIR band, this version contains important updates with respect to previous versions (such as updated radiometric correction parameters, polarization effects, and reference blackbody emissivity) and is virtually identical to the most 
recent version v201202, however there is a concern that a small non-linearity is still unaccounted for. For further details on the instrument, its calibration, and performance, we refer to Kuze et al. $(2009,2014,2016)$.

\section{Retrieval}

To infer methane profiles from GOSAT-TIR measurements, a forward model $\boldsymbol{F}$ is needed, that simulates the radiance measurement $\boldsymbol{r}$ as function of the atmospheric state vector,

$\boldsymbol{r}=\boldsymbol{F}(\boldsymbol{x}, \boldsymbol{b})+\boldsymbol{e}_{\boldsymbol{y}}$,

where $\boldsymbol{e}_{\boldsymbol{y}}$ comprises forward model error and instrument error including the measurement noise. The state vector $\boldsymbol{x}$ contains all parameters to be retrieved from the measurement and consists of the methane profile (defined over 12 layers at equidistant pressure levels), the skin temperature, a spectral shift, and four scaling parameters for the total columns of $\mathrm{H}_{2} \mathrm{O}, \mathrm{HDO}, \mathrm{N}_{2} \mathrm{O}$, and a separate total $\mathrm{H}_{2} \mathrm{O}$ column to calculate the water-continuum. The inclusion of the latter water column in the state vector is necessary as the forward model can not capture all water-related spectral features of both the water vapour absorption lines and the water continuum contribution with a single parameter. The forward model parameter $\boldsymbol{b}$ symbolises all model parameters that require prior knowledge, such as instrument parameters, atmospheric pressure, and temperature profiles.

\subsection{Forward model}

To simulate line-by-line radiance spectra at the top of the model atmosphere, we account for the Planck radiation of the Earth surface and its atmosphere as radiation source and ignore the solar contribution to the spectrum analogous to e.g. Wassmann et al. (2011). For a non-scattering atmosphere, the down-welling radiation is reflected by the Earth's surface assuming isotropic Lambertian reflection. The down-welling is calculated by the means of a 4-point Gaussian quadrature. The wavelength-dependent emission by the Earth's surface is a function of surface temperature and the surface emissivity. Here, the surface reflection of down-welling atmospheric radiation is governed by the emissivity, following Kirchhoff's law. We determine the initial surface emissivity over land with the high spectral resolution algorithm developed by Borbas (Borbas et al., 2007; Borbas and Ruston, 2010) using the University of Wisconsin Baseline Fit (UW-BF) Emissivity Database (Seemann et al., 2008) as input. For water surfaces, we use the IRSSE model by van Delst and Wu (2000) to calculate the surface emissivity in RemoTeC. This model is an update of Wu and Smith (1997) and the calculated emissivity is a function of sea-roughness as determined by the wind speed, viewing angle, and wavelength of the radiation. Furthermore, we consider atmospheric absorption by $\mathrm{H}_{2} \mathrm{O}, \mathrm{CH}_{4}$, $\mathrm{N}_{2} \mathrm{O}$, and $\mathrm{CO}_{2}$ from the HITRAN 2008 database (Rothman et al., 2009) and describe atmospheric continuum absorption using the MT_CKD_2.4 model by Mlawer et al. (2012) to account for broad-band contributions from water, carbon dioxide, oxygen, nitrogen, and ozone. Here the continuum contribution by water is calculated separately, including the foreign and self continuum. The surface temperature and wind speed as well as the water vapour and temperature profile of the atmosphere, needed to initialise the retrieval, are taken from European Centre for Medium-Range Weather Forecast (ECMWF) ERA interim data set (Dee et al., 2011). The $\mathrm{CH}_{4}$ and $\mathrm{N}_{2} \mathrm{O}$ profiles are adapted from MACC-II (Bergamaschi and Alexe, 2014), and $\mathrm{CO}_{2}$ from CarbonTracker CT2013 (Peters et al., 2007; CarbonTracker website, 2018). The lineby-line calculation follows the RemoTeC implementation as described in Butz et al. (2011) and Schepers et al. (2012).

Finally the line-by-line spectra are degraded to the spectral resolution of the sensor using TANSO-FTS spectral response. Numerically, the forward model is implemented in the RemoTeC retrieval tool (Butz et al., 2011; Schepers et al., 2012) to benefit from the overall processing properties of this framework.

\subsection{Inversion}

The goal of a retrieval is to determine the atmospheric state vector $\boldsymbol{x}$ in Eq. (1) by inverting the forward model $\boldsymbol{F}$. The RemoTeC inversion module is described in detail by Butz et al. (2011) and in this section we summarise the inversion aspects that are relevant for this study.

Since the forward model $\boldsymbol{F}$ is generally not linear in the state vector $\boldsymbol{x}$, Eq. (1) is inverted with a Gauss-Newton iteration scheme. This means that $\boldsymbol{F}$ is linearised in each iteration step by a Taylor expansion around the solution of the previous step, starting with a first guess state vector $\boldsymbol{x}_{0}$. Equation (1) can be rewritten as:

$\boldsymbol{y}=\mathbf{K} \boldsymbol{x}+\boldsymbol{e}_{\boldsymbol{y}}$,

where $\boldsymbol{y}=\boldsymbol{r}-\boldsymbol{F}\left(\boldsymbol{x}_{i-1}\right)+\mathbf{K} \boldsymbol{x}_{i-1}$ is the so-called measurement vector with $\boldsymbol{x}_{i-1}$ the state vector of the previous iteration step and $\mathbf{K}$ is the Jacobian matrix.

To infer a vertical methane profile from GOSAT-TIR measurements represents an ill-posed problem requiring regularisation. Several techniques have been developed to solve such problems and in this study we employ 0-th order Tikhonov regularisation (Tikhonov, 1963; Phillips, 1962; Twomey, 1963):

$\boldsymbol{x}_{\gamma}=\min _{\boldsymbol{x}}\left(\|(\mathbf{K} \boldsymbol{x}-\boldsymbol{y})\|^{2}+\gamma^{2}\|\boldsymbol{x}\|^{2}\right)$,

where $\boldsymbol{x}_{\gamma}$ is the solution vector of the minimisation problem, $\|(\mathbf{K} \boldsymbol{x}-\boldsymbol{y})\|^{2}$ is the least squares norm and $\|\boldsymbol{x}\|^{2}$ is the side constraint. $\gamma$ is the regularisation parameter and has to be carefully chosen to balance the two contributions of the cost function. In this study, we employ the $L$-curve paradigm to find the appropriate value for the regularisation parameter 
(Hansen, 1992), which is discussed extensively in the literature (Hasekamp and Landgraf, 2001; Steck, 2002; Butz et al., 2011). The solution of Eq. (3) is:

$\boldsymbol{x}_{\gamma}=\mathbf{D} \boldsymbol{y}$,

where,

$\mathbf{D}=\left(\mathbf{K}^{\mathrm{T}} \mathbf{K}+\gamma^{2} \mathbf{I}\right)^{-1} \mathbf{K}^{\mathrm{T}} \mathbf{S}_{\boldsymbol{y}}^{-\frac{1}{2}}$,

is the pseudo-inverse of $\mathbf{K}$ or the contribution matrix, $\mathbf{S}_{\boldsymbol{y}}$ the measurement noise covariance matrix and $\mathbf{I}$ represents the unity matrix. Moreover, the retrieval noise covariance matrix is given by:

$\mathbf{S}_{\boldsymbol{x}}=\mathbf{D S}_{\boldsymbol{y}} \mathbf{D}^{\mathrm{T}}$

where $\mathbf{S}_{\boldsymbol{y}}$ is measurement noise covariance.

The retrieved vector $\boldsymbol{x}_{\gamma}$ is a weighted average of the true atmospheric state vector $\boldsymbol{x}_{\text {true }}$,

$\boldsymbol{x}_{\gamma}=\mathbf{A} \boldsymbol{x}_{\text {true }}+\boldsymbol{e}_{\boldsymbol{x}}$

due to the required regularisation. Here $\mathbf{A}=\mathbf{D K}$ is the averaging kernel and $\boldsymbol{e}_{\boldsymbol{x}}=\mathbf{D} \boldsymbol{e}_{\boldsymbol{y}}$ is the error in the state vector caused by measurement errors. Effectively, the averaging kernel degrades the true profile to the vertical resolution of the retrieval and also defines the null-space contribution of the true state vector $\boldsymbol{x}_{\text {true }}$, namely:

$\boldsymbol{x}_{\text {null }}=(\mathbf{I}-\mathbf{A}) \boldsymbol{x}_{\text {true }}$,

comprising the contribution of the state vector, that cannot be inferred from the measurement.

Figure 1 shows a typical averaging kernel for GOSAT-TIR retrievals.

It indicates a peak around $9 \mathrm{~km}$, and the retrieval sensitivity drops quickly for altitudes close to surface. This loss in sensitivity to methane concentrations at low altitudes can be understood as follows. Line features only show up in the spectrum if the local photon field is not at equilibrium with the atmospheric radiance corresponding to the Planck curve governed by the ambient temperature. In general, the skin temperature of the Earth is similar to the temperature of the lowest layers of the atmosphere, and the radiance emitted by the Earth's surface is in accordance with the radiance of those atmospheric levels. So, molecular line features are only weakly imprinted on the recorded spectrum, and hence, the sensitivity is very limited.

The DOFS is defined by:

$\mathrm{DOFS}=\operatorname{Tr} \mathbf{A}$,

and can be interpreted as the amount of independent pieces of information that can be retrieved from the measurement. In the case of GOSAT-TIR retrievals the DOFS is $\approx 1.0$ for

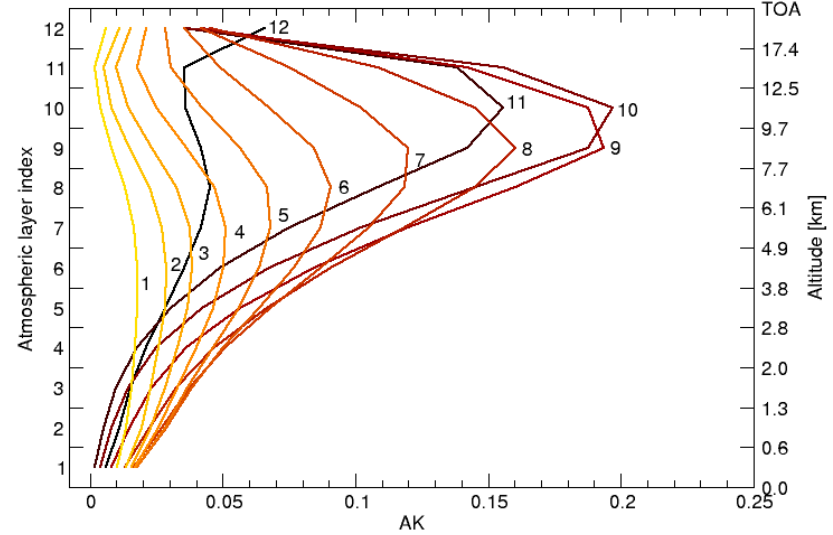

Figure 1. A typical averaging kernel for GOSAT-TIR daytime measurements over land. The colour coding is such that dark colours correspond to the averaging kernels at high altitudes and the bright colours to low altitudes. The numbers next to the curves refer to the corresponding atmospheric layer index as is indicated on the left side of the graph.

scenes with a limited temperature contrast (nighttime measurements or daytime measurements over the ocean) and $\approx 1.1$ for daytime measurements over land with on average a slightly higher temperature contrast.

When one considers the retrieved profile $\boldsymbol{x}_{\gamma}$ in Eq. (3) as the methane data product, one has to account for the retrieval sensitivity given by the averaging kernel. Alternatively, one may consider the vertical profile after adding an estimate of the null-space contribution to $\boldsymbol{x}_{\gamma}$, namely:

$\boldsymbol{x}_{\mathrm{CH}_{4}}=\boldsymbol{x}_{\gamma}+(\mathbf{I}-\mathbf{A}) \boldsymbol{x}_{\mathrm{apr}}$,

with an a priori estimate of the true profile $\boldsymbol{x}_{\text {apr }}$ coming from e.g. an independent measurement or a chemical transport model forecast. For the purpose of our study, it is also valuable to calculate the total methane column $c_{\mathrm{CH}_{4}}$ from Eq. (10), namely:

$c_{\mathrm{CH}_{4}}=\boldsymbol{C} \boldsymbol{x}_{\mathrm{CH}_{4}}$,

where $\boldsymbol{C}$ is the column operator, effectively summing all partial columns in $\boldsymbol{x}_{\mathrm{CH}_{4}}$. This implies that $\boldsymbol{x}_{\mathrm{CH}_{4}}$ is given in column units, e.g. $\mathrm{cm}^{-2}$. To indicate the actual retrieval sensitivity the so-called column averaging kernel is a useful quantity, defined by the averaging kernel $\mathbf{A}$ and column operator C (Borsdorff et al., 2014),

$\boldsymbol{A}_{\mathrm{col}}=\boldsymbol{C} \mathbf{A}$,

as well as the corresponding retrieval error variance,

$\mathrm{s}_{\mathrm{CH}_{4}}=\boldsymbol{C} \mathbf{S}_{\boldsymbol{x}} \boldsymbol{C}^{\mathrm{T}}$.

A typical column averaging kernel for land and ocean scenes at daytime and nighttime is depicted in Fig. 2. It shows a 


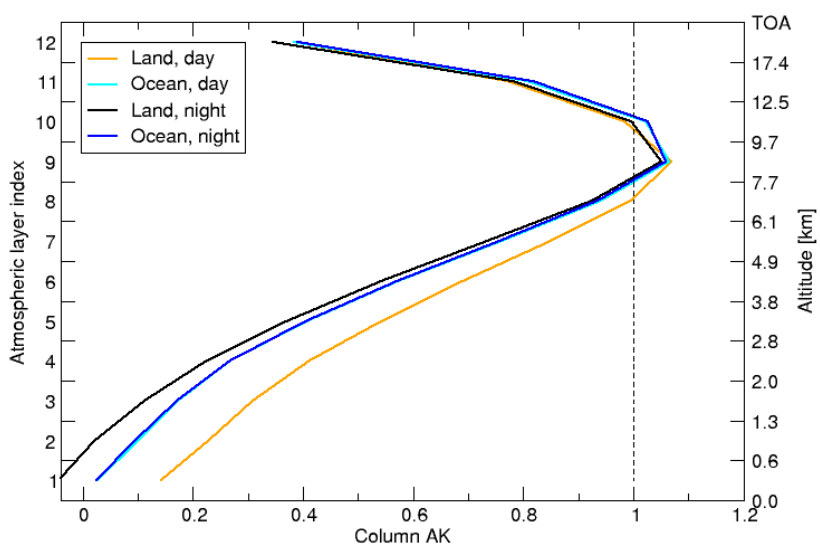

Figure 2. The average of all column averaging kernels in this study for different scenes and measurement times. Daytime and nighttime measurements over land are depicted as orange and black curves and over the ocean in dark blue and cyan curves, respectively.

clear drop-off in sensitivity towards the lower layers of the atmosphere and also enhanced sensitivity to the lower layers for daytime measurements over land scenes can be discerned. This enhancement is because of the temperature contrast, which is larger for daytime than for the nighttime measurements and larger for measurements over land than over the ocean.

A priori knowledge on methane has a significant impact on the profile $\boldsymbol{x}_{\mathrm{CH}_{4}}$. This is even the case for the total column as can be determined by applying the column operator $C$ to Eq. (10). The relative contribution of the null-space term $\boldsymbol{C}(\mathbf{I}-\mathbf{A}) \boldsymbol{x}_{\mathrm{apr}}$ is typically in the order of $30 \%$. This can be estimated from Fig. 2, under the assumption that methane shows a constant profile as function of altitude, by integrating the column averaging kernel over altitude and compare this value to the case of an ideal column averaging kernel of 1 over all altitudes (indicated by a dashed line in the figure). Therefore, the reference profile must be of sufficient quality not to govern the uncertainty in $\boldsymbol{x}_{\mathrm{CH}_{4}}$.

\subsection{Validation approach}

Ideally, the validation of the retrieved GOSAT methane profile relies on independent validation measurements of the vertical methane distributions. A promising data source of validation is given by AirCore balloon soundings reaching a height up to $30 \mathrm{~km}$ (Karion et al., 2010). However, the development of an extended observation framework is still on-going and to this day the number of usable soundings is very limited, causing poor statistics for validation purposes. Therefore, we decided not to consider these observations in our study. Another validation possibility is to use airborne measurements within the HIPPO project conducted in the years 2009-2011. Here methane profiles are measured up to $\approx 13 \mathrm{~km}$. However, in our study these measurements are used to radiometrically correct the GOSAT measurements, as will be shown in Sect. 4, and can therefore not be used for validation purposes. Finally, during the ascent and decent of commercial airlines the methane distribution is measured in situ close to airports up to typical flight heights of $10 \mathrm{~km}$. Two examples of such measurement frameworks are CONTRAIL (comprehensive observation network for trace gases by airliner) (Machida et al., 2008; Inoue et al., 2014) and CARIBIC (civil aircraft for the regular investigation of the atmosphere based on an instrument container; Brenninkmeijer et al., 2007). Obviously, these measurements are limited in altitude, typically to $10 \mathrm{~km}$, and therefore lack an important part of the profile to which the GOSAT-TIR measurement is sensitive to. All in all, high-quality measurements of methane profiles are sparse and due to the required colocation between GOSAT measurements and the available reference measurements, we estimate the number of validated profiles to be too limited for a validation of our product.

A common approach to validate methane total column retrieval from shortwave infrared (SWIR) measurements is to compare the retrieved column to co-located ground-based measurements of the Total Carbon Column Observing Network (TCCON; Wunch et al., 2011). In this particular case of the SWIR wavelength regime, both the ground-based and satellite observations show homogeneous methane retrieval sensitivity over all atmospheric altitudes, leading to highly accurate estimates of the total column of methane rather than a profile. Because of the lack of other validation measurements, we decided to use these data for our product validation. In first instance, we derive a methane profile employing the MACC-II repository (Bergamaschi and Alexe, 2014), which delivers global methane fields on a daily basis, to extract an a priori estimate $\boldsymbol{x}_{\text {apr }}$. This estimate is subsequently scaled to the total columns of co-located TCCON measurements. The profile is used to derive the total methane column as described by Eq. (11) and so the comparison with TC$\mathrm{CON}$ total columns ensures the same null-space contribution in the GOSAT TIR and the validation estimate of the total column. Moreover, the MACC/TCCON profile can be used to compare to the methane profile $\boldsymbol{x}_{\gamma}$ in Eq. (7) and $\boldsymbol{x}_{\mathrm{CH}_{4}}$ in Eq. (10).

\section{$3.4 \mathrm{CH}_{4}$ retrievals}

We start our validation analysis comparing the retrieved total methane columns from GOSAT-TIR measurements over TCCON stations with the corresponding measurements at the site. To minimise the interfering effect of scattering by clouds, hazes, cirrus, and/or aerosols, in this study we focus on clear-sky conditions. This implies that a cloud-filter needs to be employed. Although, within the RemoTeC-framework, a well-tested cloud filter is available for daytime measurements over land based on SWIR and NIR spectra, there is no equivalent for the TIR spectrum. Particularly to filter nighttime measurements or measurements over the ocean, one has to resort to a cloud filter rooted in the TIR spectra. There- 


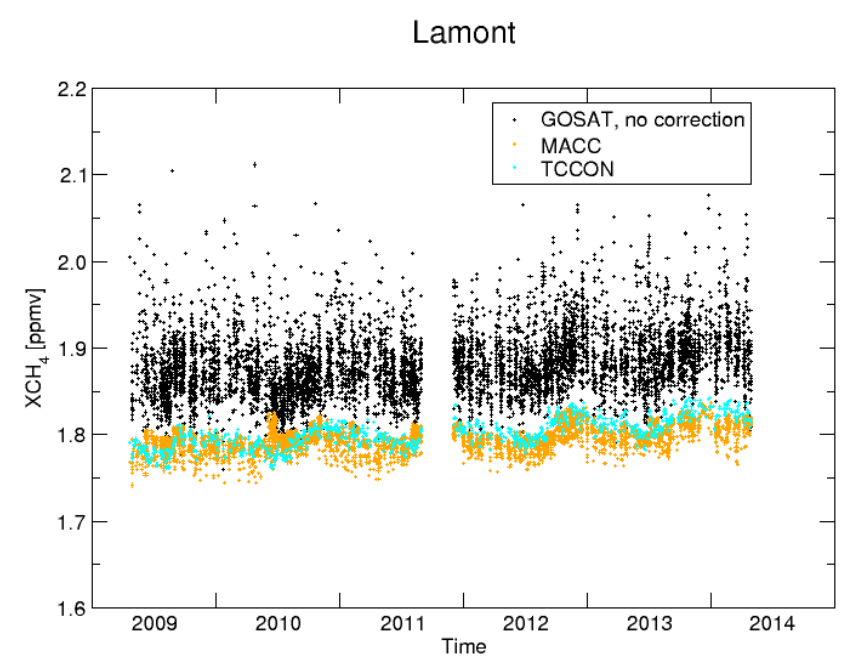

Figure 3. Total methane columns as a time series over Lamont. In black the GOSAT-TIR retrievals are shown. In orange and cyan, the corresponding (non-scaled) MACC and TCCON total columns are shown, respectively.

fore, we make use of the fact that clouds generally change the effective light path by scattering, and the retrieved columns differ from the actual columns. For cloud screening of the data set, we consider the difference between the retrieved $\mathrm{N}_{2} \mathrm{O}$ total column and the MACC $\mathrm{N}_{2} \mathrm{O}$ total column. To account for an overall bias in the MACC $\mathrm{N}_{2} \mathrm{O}$ columns, we define a dynamical mean $x$ of the $\mathrm{N}_{2} \mathrm{O}$ column errors such that cumulative number of converged retrievals in the range $[x-3 \%, x+3 \%]$ are maximised. All data within this interval are considered in the successive analysis to be cloud filtered. In Sect. 4.1 the cloud filter is investigated in more detail. Moreover, data are filtered using a stringent normed Pearson's chi-squared criterium of $\chi^{2}<3.0$ for the spectral fit quality. Figure 3 depicts the comparison between retrieved total methane columns from GOSAT-TIR measurements and co-located TCCON observations. Although the GOSAT methane results capture the seasonal variation, they also clearly show a large and persistent bias of about $4.6 \%$.

This bias shows little variation when compared to nine other TCCON sites (Bialystok, Bremen, Darwin, Lauder, Orleans, Park Falls, Reunion, Sodankyla, and Wollongong) as depicted in Fig. 4.

The error bars indicate the $1 \sigma$ standard deviation of the difference between GOSAT and TCCON and correspond to a typical value of $2 \%$. The propagation of the measurement noise into the retrieved total column amounts to retrieval error $\mathrm{s}_{\mathrm{XCH}_{4}} \approx 0.8 \%$ and explains only a part of spread. The average bias is $+4.6 \%$, whereas the station-to-station variation in the bias is much smaller $(0.4 \%)$. The accuracy of the total columns from the MACC repository, used as prior in the retrieval product, is also estimated to be of the order of $2 \%$. This estimation is based on the study in Landgraf et al. (2016) where methane fields from the TM5 model are

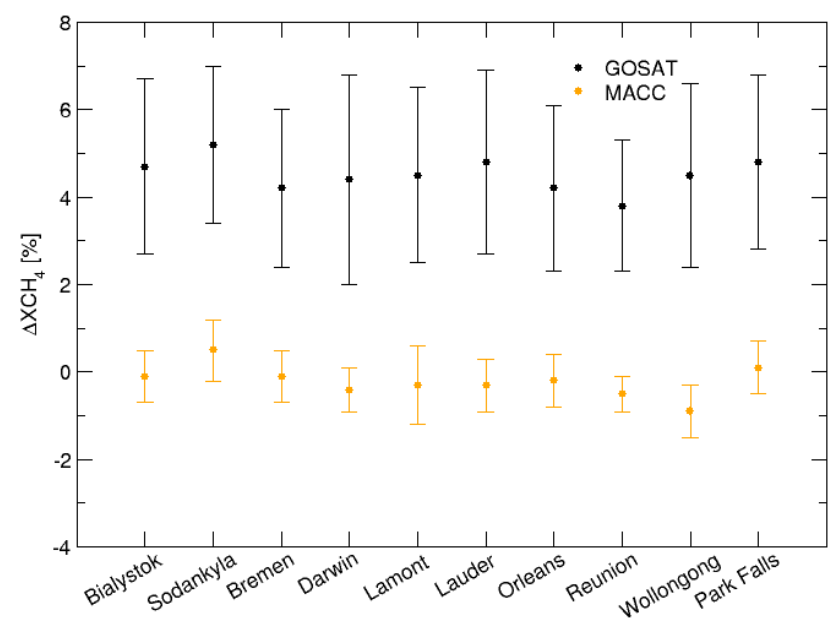

Figure 4. Average of the relative total methane column with respect to TCCON measurements for GOSAT-TIR retrievals (black) and the (non-scaled) MACC prior (orange). The bars indicate the spread in the data ensemble.

compared against GOSAT-SWIR retrievals and it was found that on average the standard deviations are well within $1 \%$, with sporadic outliers up to $3 \%$. It is noted that the TM5 model runs were conducted with methane constraints only taken from the measurements of the NOAA-ESRL global monitoring network, whereas within the MACC repository the GOSAT-SWIR measurements are also taken as input. In a study by Bergamaschi et al. (2009), the TM5 model with SCIAMACHY methane measurements as input, is verified. Also in this study only small deviations are found, typically in the order of $1 \%$. This is even true for the stratosphere, where the model uncertainty is generally larger. Therefore, we believe that the estimation of $2 \%$ on the accuracy of the total columns from the MACC repository is reasonable, even on the safe side. Since it typically contributes for $30 \%$ to the retrieved total column, it contributes with $\approx 0.6 \%$ to the error budget. Finally, the precision and accuracy of the methane TCCON measurements are both estimated to be $<0.3 \%$ (TCCON Data Description website, 2018). Overall these relatively small error contributions imply that further sources of uncertainties exist, e.g. radiometric calibration and forward model errors.

To better understand the induced errors, we compare the average GOSAT-TIR methane profile $\boldsymbol{x}_{\mathrm{CH}_{4}}$ over the TCCON site Bialystok with the averaged MACC/TCCON profile in Fig. 5.

The deviation between the two profiles peaks around $9 \mathrm{~km}$, which corresponds to the altitude of maximum retrieval sensitivity. This suggests that the altitude dependent bias in this figure finds its origin in the altitude dependent sensitivity. The depicted difference is representative for all TCCON stations. 


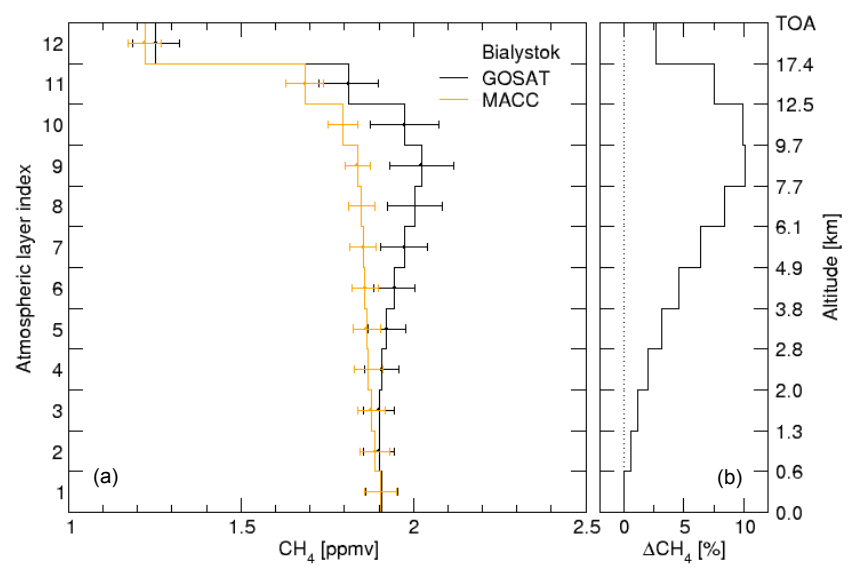

Figure 5. (a) Average methane profile retrieved from GOSAT-TIR spectra (black) over TCCON station Bialystok and from the MACC repository (orange) scaled such that the total column equals the corresponding TCCON total column measurement. The bars indicate the spread in the data ensemble. (b) The relative difference between the averaged retrieved GOSAT TIR and MACC methane profiles. It is noted that the two panels have different horizontal scales.

Therefore, it is insightful to compare the retrieved GOSAT-TIR profiles $\boldsymbol{x}_{\gamma}$ in Eq. (4) with the smoothed MACC profile by applying the averaging kernel as indicated in Eq. (7). Figure 6 shows corresponding results for the TCCON site Bialystok.

The bias on $\boldsymbol{x}_{\gamma}$ is much more constant over altitude, but still shows some striking vertical features with biases peaking around $9 \mathrm{~km}$ with the highest sensitivity to methane, a negative lobe towards lower altitudes and a sharp drop-off for the upper layers of the atmosphere.

To survey the retrieval performance at all TCCON sites mentioned in Table 1, Fig. 7 shows the error bar chart of the mean retrieval bias at 2 and $9 \mathrm{~km}$.

Overall we see a similar behaviour for all TCCON sites and the station-to-station bias variation is small $(\approx 0.6 \%)$. Moreover, we find an interesting variation of biases for different types of observations, where we distinguish between daytime and nighttime observations and land and ocean scenes. In Fig. 7, the bias at $9 \mathrm{~km}$ is systematically lower for the daytime-land measurements than for the other three scenes, who are amongst themselves very comparable. At $2 \mathrm{~km}$ this behaviour is reversed; daytime-land measurements are systematically higher. For the interpretation, we have to consider the different retrieval sensitivity as indicated in Fig. 2. During the day over land, the thermal contrast in the lower atmosphere is larger than for the other three cases and therefore the retrieval sensitivity increases accordingly. This enhancement goes along with larger biases.

Overall we conclude that the biases in the retrieved $\mathrm{CH}_{4}$ profiles are significant and require a mitigation strategy. A straightforward scaling of the retrieved profile by a certain factor is not sufficient because it cannot account for the al-

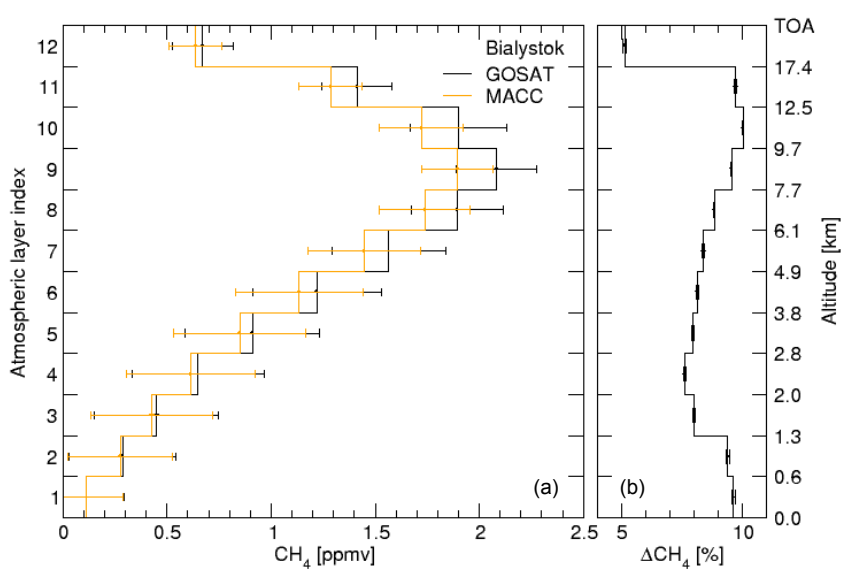

Figure 6. (a) Averaging kernel-smoothed profiles from GOSAT daytime measurements over land (black) and MACC (orange) at TCCON station Bialystok. The bars indicate the spread in the data ensemble. (b) The relative difference between the profiles. The bars pertain to the $1 \sigma$ uncertainty of the averaged ratio, derived from the instrument noise propagation.

titude dependent biases for both $\boldsymbol{x}_{\gamma}$ and $\boldsymbol{x}_{\mathrm{CH}_{4}}$. Therefore, in the next section we will discuss a scheme to correct radiometrically the GOSAT-TIR measurements as part of the inversion.

\section{Bias correction scheme}

Instead of correcting the biases at the level of geo-physical methane profiles, we consider an approach to quantify spectral features of radiometric biases of the GOSAT-TIR measurements. The observed methane bias finds its origin in the discrepancy $\boldsymbol{e}_{\boldsymbol{y}}$ between forward model $\boldsymbol{F}$ and measurement $\boldsymbol{r}$ in Eq. (1). Although we cannot distinguish between forward model errors and instrumental errors, we can investigate the spectral properties of this discrepancy. Fixing the $\mathrm{CH}_{4}$ and $\mathrm{N}_{2} \mathrm{O}$ profile to accurate a priori knowledge, we retrieve all other parameters of the state vector, i.e. the skin temperature, the spectral shift, the total columns of $\mathrm{H}_{2} \mathrm{O}$ and $\mathrm{HDO}$, and a separate total $\mathrm{H}_{2} \mathrm{O}$ column to calculate the water-continuum independently from the water vapour absorption lines. Analysing spectral fit residuals guides us to identify spectral components of the radiometric bias, that interfere with the atmospheric methane absorption. For this purpose we used $\mathrm{CH}_{4}$ and $\mathrm{N}_{2} \mathrm{O}$ data from the HIPPO campaigns II and III (held in, respectively, October 2009 and March 2010). The HIPPO data contains vertical profiles of many relevant species and atmospheric parameters, setting strong constraints on the estimated state of the atmosphere. Although most of the measurements are taken over the $\mathrm{Pa}$ cific ocean, in both campaigns vertical profiles have also been recorded over North America, and, in the case of campaign III, also over New Zealand. Therefore, these cam- 

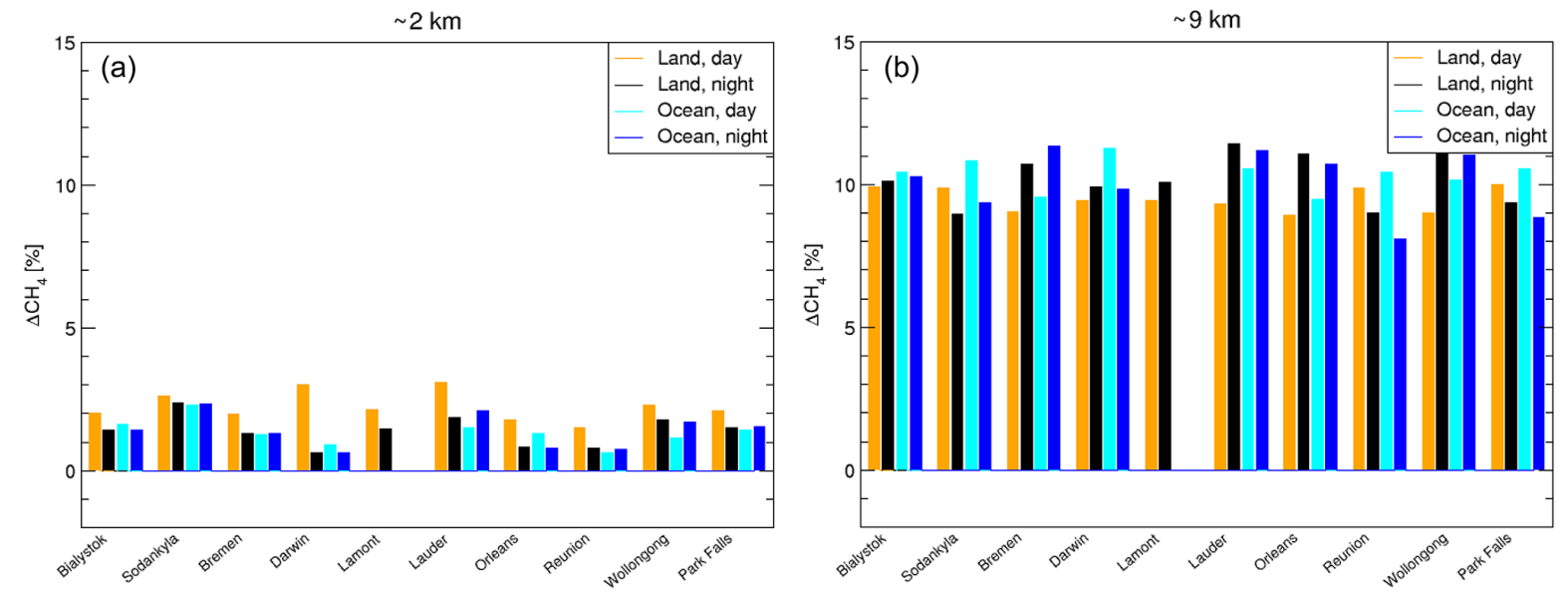

Figure 7. Bar chart of the methane profile bias over ten different TCCON stations listed in Table 1, with the MACC/TCCON profiles as reference. The data are divided for different scenes; land and ocean scenes during daytime (orange and cyan, respectively) and nighttime (black and blue, respectively). In (a) the deviation is shown for an altitude of $\approx 2 \mathrm{~km}$ and in (b) of $\approx 9 \mathrm{~km}$.

paigns seem to suit our need to include as many as possible different scenes to investigate systematics in spectral residuals. With the co-location criteria $\left(\Delta \mathrm{lat}=5^{\circ}, \Delta \mathrm{lon}=8^{\circ}\right.$, and $\Delta \mathrm{t}=2 \mathrm{hrs}$ ), the amount of unique HIPPO-GOSAT measurement pairs is $\approx 300$.

Typically, the spectral residuals of this fit are very small, as can be seen in Fig. 8 .

In the second panel, the noise level of a single measurement is indicated by the dashed line $(7 \times$ $\left.10^{-8} \mathrm{~W} \mathrm{~m}^{-2} \mathrm{srcm}^{-1}\right)$. The residual averaged over all colocated HIPPO-GOSAT pair is depicted in the third panel. Note that the spectral bias is less than $1 \%$ of the continuum level at $1210 \mathrm{~cm}^{-1}$ for the depicted spectrum, but causes biases in the retrieved methane product up to $10 \%$ at $9 \mathrm{~km}$ altitude.

The comparison of the second and third panel of Fig. 8 indicates that most residuals average out for larger data sets. This may be due to random noise contributions but also spectral features which change from observation to observation in a non-random manner are suppressed by the averaging. Here the principal component analysis (PCA) provides an adequate means of detecting non-random contributions in the fit residuals. It is based on an eigenvalue analysis of the covariance matrix of the underlying data set. The first principal component corresponds to the eigenvector with the largest possible variance, and for each succeeding component the variance degrades to lower values. By definition, the different principal components are uncorrelated.

Let $\mathbf{X}$ be the data matrix, consisting of 300 spectral residuals for all co-located HIPPO-GOSAT pairs, assuming that the mean residual is subtracted. Its covariance matrix $\mathbf{C}$ is then:

$\mathbf{C}=\mathbf{X X}^{\mathrm{T}} /(n-1)$,

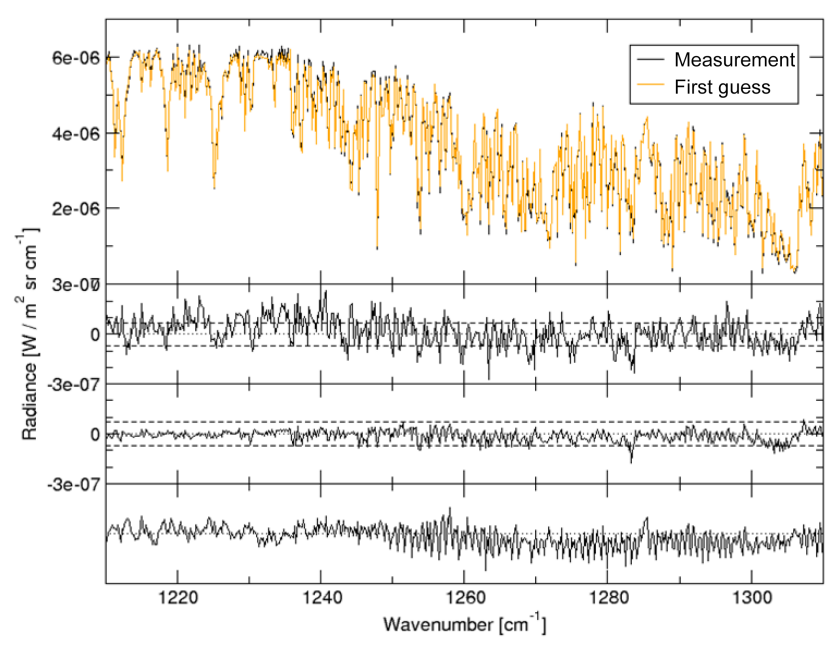

Figure 8. Comparison of GOSAT-TIR measurement with a forward model calculation based on methane profiles as measured during the HIPPO campaigns. The upper panel shows a single GOSAT measurement (black) and the forward calculation based on the colocated HIPPO measurement (orange), and in the second panel the residual is shown. The third panel depicts the average residual of all 300 GOSAT-HIPPO pairs used to centre all residuals in the principal component analysis. In the bottom panel the first principal component of this analysis is pictured.

which is symmetric and the eigenvalue problem can therefore be written as:

$\mathbf{C}=\mathbf{V} \mathbf{L} \mathbf{V}^{\mathrm{T}}$,

with $\mathbf{L}$ a diagonal matrix with the eigenvalues of $\mathbf{C}$ and $\mathbf{V}$ the set of eigenvectors. When $\mathbf{L}$ contains the eigenvalues in decreasing order, then the $i$ th principal component is the $i$ th column of $\mathbf{V}$. 
The first principal component is shown in the fourth panel of Fig. 8. The strongest spectral features in this component show above $1250 \mathrm{~cm}^{-1}$ and follow mostly $\mathrm{N}_{2} \mathrm{O}$ and $\mathrm{CH}_{4}$ lines. In fact, this wavelength range corresponds to the part of the measurement where $\mathrm{N}_{2} \mathrm{O}$ and $\mathrm{CH}_{4}$ are strongly interfering. Between 1210 and $1250 \mathrm{~cm}^{-1}$ some weak features coincide with water and methane lines. These coincidences may point to errors in the spectroscopy databases. However, they may also point to broadband radiometric biases, such as atmospheric continuum contributions or non-linear instrumental effects. The impact of such effects on the spectrum is a function of the total optical density, explaining the different size of the spectral features in the component below and above $1250 \mathrm{~cm}^{-1}$.

\subsection{Bias-corrected methane retrievals}

The first step of assessing the radiometric bias comprises the subtraction of the averaged residual from every GOSAT measurement before conducting a retrieval. In addition, we modify the forward model $\boldsymbol{F}$ by,

$\widetilde{\boldsymbol{F}}(\boldsymbol{x})=\boldsymbol{F}(\boldsymbol{x})+\sum_{i} a_{i} \boldsymbol{p}_{i}$,

adding principal components $\boldsymbol{p}_{i}$ with the amplitudes $a_{i}$ to be determined by the retrieval. Obviously, every addition of a principal component improves the spectral fit quality indicated by smaller $\chi^{2}$ values, but on the other hand, it increases noise propagation and instability of the retrieval. Therefore, a trade-off needs to be made between bias-mitigation and reduced precision. Adding the first principal component to $\widetilde{\boldsymbol{F}}$, improves the overall shape of the inferred methane profile, lowering the overall bias. However, the noise propagation is only slightly increased with respect to the retrievals without this retrieved scaling parameter. Accounting for additional principal components leads to hardly any improvement in the bias but does increase the standard deviation in the differences between retrieved and reference methane profiles and is henceforth not considered in this study.

The effect of including this bias-correction scheme in the retrieval algorithm on the retrieved methane profile is depicted in Fig. 9.

On the left in Fig. 9, the profiles from bias-corrected GOSAT-TIR measurements are depicted for different scenes, with the scaled MACC profile as a reference. It is noted that only the MACC profile for the daytime land case is depicted as the profiles for the other scenes are very similar and have been left out for clarity. On the right the averaged difference between GOSAT and MACC is depicted and it clearly shows the bias in the profiles is almost fully corrected for. The bias is within $2 \%$ over the whole altitude range. Also the spread in the ensemble, given by the error bars, is lower than in the non-corrected case (from $\approx 0.10$ to $\approx 0.08$ ppmv at $9 \mathrm{~km}$ ). In addition, the different retrieval performances for daytime and nighttime measurements, observations over land and ocean

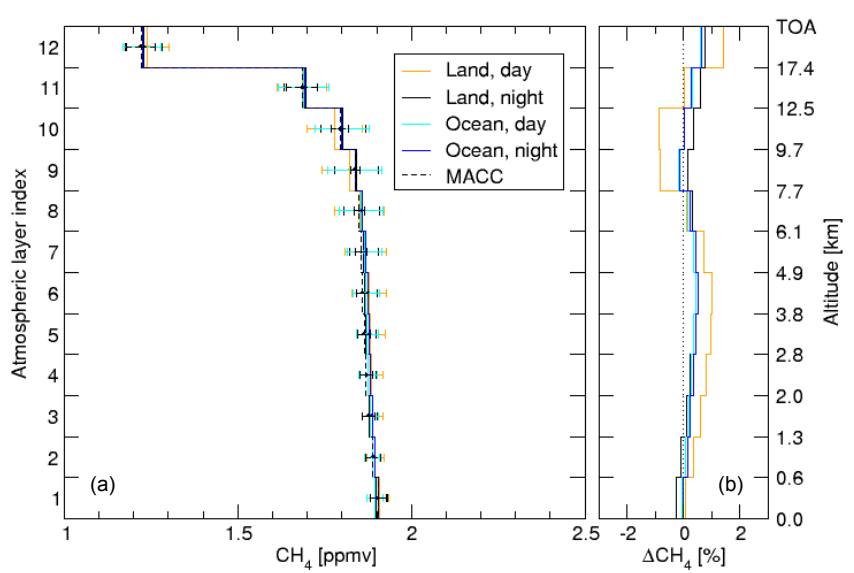

Figure 9. (a) Retrieved methane profiles from GOSAT-TIR measurements over TCCON station Bialystok with the bias-correction scheme included in the retrieval algorithm. The data are divided for different scenes; land and ocean scenes during daytime (orange and cyan, respectively) and nighttime (black and blue, respectively). The dashed lines refer to the MACC profiles for the daytime land scenes, and are very similar to the profiles for the other 3 scenes and have been left out for clarity. (b) The relative difference between the GOSAT-TIR retrievals and the MACC profiles.

have been reduced and the daytime measurements over land are in line with the other three types of measurements.

For the other TCCON stations similar behaviour is found as can be seen in Fig. 10.

For the retrieved methane concentration at $9 \mathrm{~km}$ altitude, the mean bias is $-0.08 \%$ and the $1 \sigma$ station-to-station variation in the bias is $0.76 \%$. At this altitude, the discrepancy between daytime over-land scenes and the other three scenes is small (mean biases are respectively -0.31 and $-0.01 \%$; station-to-station variations are 0.83 and $0.72 \%$ ). For $2 \mathrm{~km}$ altitude, we find that daytime over-land measurements show a systematic positive bias over all TCCON stations (mean bias is $0.97 \%$ with a station-to-station variation of $0.53 \%$ ), whereas for the nighttime and ocean measurements, the corresponding biases are much smaller (mean of 0.07 and a variation of $0.16 \%$ ). The daytime over-land biases may be explained by the fact that the HIPPO measurements are predominantly performed over the Pacific, and the few over-land measurements are not sufficiently different to fully account for the variability in the spectral residuals of all different scenes. Therefore, it may be that the correction is most applicable for scenes with a low thermal contrast. In the future, this shortcoming of our bias correction can be improved upon by an extended ensemble of airborne measurements, including over-land $\mathrm{CH}_{4}$ and $\mathrm{N}_{2} \mathrm{O}$ measurements.

After establishing the bias correction, we finally consider the efficiency of the TIR cloud filter as discussed in Sect. 3.4. For GOSAT daytime over-land measurements, we compare the efficiency of the TIR cloud filter with that of the RemoTeC cloud screening for the SWIR retrievals. Table 1 dis- 

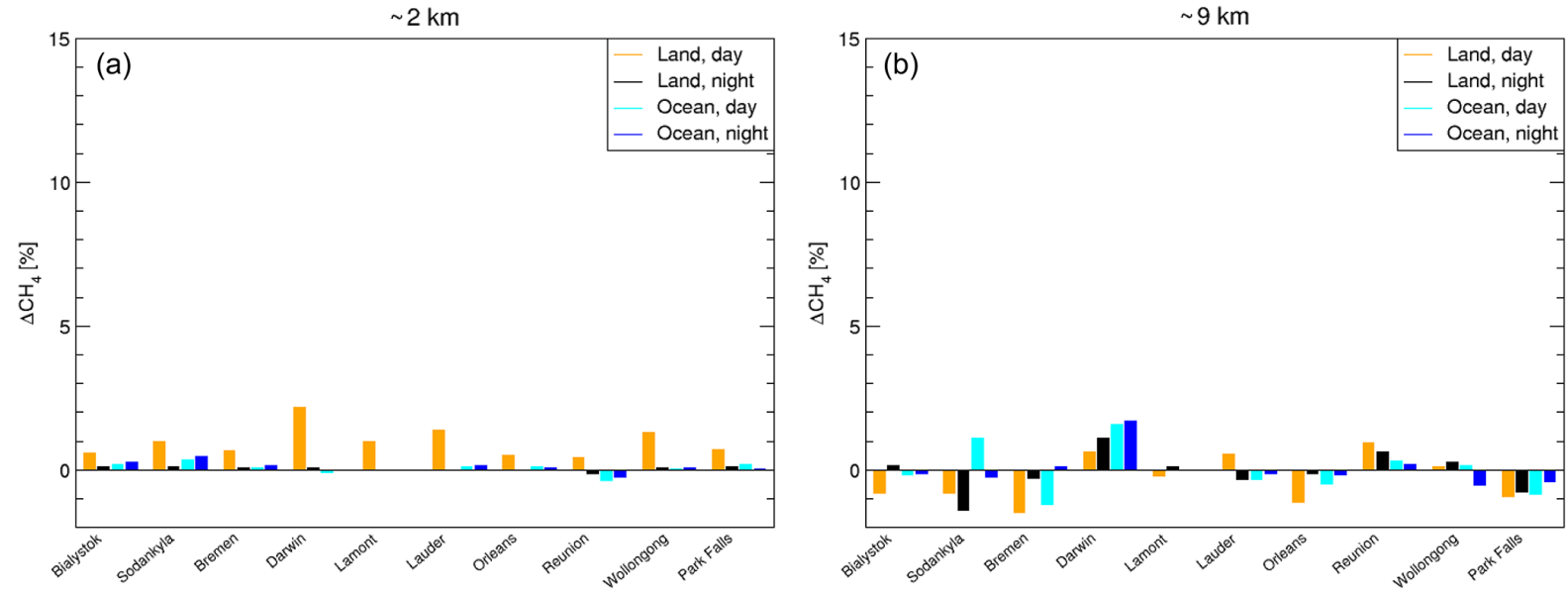

Figure 10. Bar-graphs for the relative deviation in the partial methane column at $\approx 2 \mathrm{~km}$ altitude (a) and $\approx 9 \mathrm{~km}(\mathbf{b})$ for ten different TCCON stations. The data are divided for different scenes; land and ocean scenes during daytime (orange and cyan, respectively) and nighttime (black and blue, respectively ).

Table 1. Total methane column retrieval results after applying the bias-correction scheme for scenes over land during daytime. The first three columns pertain to the cloud filter, based on fit parameters of GOSAT-TIR retrievals, whereas the last three columns refer to the filtering of exploiting spectral features in GOSAT SWIR and NIR spectra. The average remaining bias is given for each TCCON station used in the current study, along with the $1 \sigma$ spread and the number of measurements passing the particular filter. The last two rows show the values for the whole ensemble.

\begin{tabular}{lrrr|rrr}
\hline & \multicolumn{3}{c|}{ TIR filtered } & \multicolumn{3}{c}{ SWIR filtered } \\
\cline { 2 - 7 } Station & $b$ & $\sigma$ & $n$ & $b$ & $\sigma$ & $n$ \\
\hline Bialystok & 0.4 & 2.2 & 3370 & 0.8 & 1.4 & 355 \\
Sodankyla & 0.7 & 1.7 & 486 & 0.9 & 0.8 & 9 \\
Bremen & 0.1 & 2.1 & 1366 & 0.2 & 1.2 & 212 \\
Darwin & 1.3 & 2.1 & 1542 & 0.5 & 1.1 & 463 \\
Lamont & 0.6 & 2.1 & 6985 & 0.4 & 1.2 & 2307 \\
Lauder & 1.3 & 3.1 & 187 & 0.4 & 1.8 & 27 \\
Orleans & 0.1 & 1.9 & 3023 & 0.4 & 1.1 & 384 \\
Reunion & 0.7 & 1.8 & 194 & 0.9 & 1.1 & 48 \\
Wollongong & 0.9 & 2.4 & 2121 & 0.6 & 1.3 & 407 \\
Park Falls & 0.3 & 2.2 & 4367 & 0.6 & 1.3 & 947 \\
$\bar{b}$ & 0.6 & 2.2 & & 0.6 & 1.2 & \\
$\sigma_{\mathrm{b}}$ & 0.4 & - & & 0.2 & - & \\
\hline
\end{tabular}

plays the average bias $b$ and its standard deviation $\sigma$ for GOSAT-TIR retrievals applying the two different cloud filters to the data. From the table it can be seen that the number of scenes $n$ passing the TIR filter is significantly higher than for the SWIR filter. The average results are consistent with both filtering methods as the mean bias of all stations is $\bar{b}=+0.6 \%$ for both cloud filters. However, the station-tostation scatter in the bias $\sigma_{\mathrm{b}}$, defined as the standard deviation of the mean biases per station, is $0.4 \%$ and $0.2 \%$ for the TIR and SWIR cloud filtered data, respectively. Also the scatter in the data are significantly lower in case of the SWIR cloud filter $(1.2 \%)$ compared to the TIR filter $(2.2 \%)$. It is noted that constraining the TIR filter criteria more stringently does not lead to a reduced scatter.

For the daytime land retrievals one may therefore consider to apply the SWIR filtering. However, this is not possible for ocean and nighttime observations. For consistency reasons we only consider TIR cloud filtering for all observations in this study.

We conclude that the cloud filter using SWIR spectral features is more able to filter GOSAT observations with respect to cloudiness than the TIR data filtering. However, on average both cloud filters are consistent and the cloud filter using TIR data does not introduce additional biases in the methane product.

\section{Conclusions}

Methane profile retrievals generally result in a positive bias when retrieved from thermal infrared spectra. In case of GOSAT TIR, this bias is $4-5 \%$ in the total methane column, and can amount to $10 \%$ at altitudes where the sensitivity peaks (typically $9 \mathrm{~km}$ ). To account for this bias, a correction scheme has been developed. It has been shown that a simple additive or multiplicative scheme may result in a sufficiently accurate total methane column product, but that such schemes are insufficient to account for non-physical structures in the retrieved profiles. In fact, these structures only yield correct total columns when they properly cancel. Especially in cases with enhanced methane abundances, in particular close to the surface or at high altitudes, this presumption may not be valid. In view of inversion schemes to determine methane sources and sinks, it is these scenes with enhanced 
methane that are most interesting, but may lead to erroneous values. Moreover, land-ocean transitions and differences between day and night are also not fully corrected for via these simple correction schemes in the case of GOSAT-TIR data.

In this study, we have developed a more elaborate bias correction scheme to account for all these aspects in methane retrievals from GOSAT-TIR spectra. The scheme is rooted in a principal component analysis of the spectral residuals between measurement and a forward model run with the best possible knowledge of the state of the atmosphere. Pivotal in this knowledge are $\mathrm{CH}_{4}$ and $\mathrm{N}_{2} \mathrm{O}$ profiles which have been derived from HIPPO air campaign data. It has been shown that accounting for the average spectral residual and including one additional fitting parameter to scale the first principal component is sufficient to account for the bias within $2 \%$ when compared to the MACC methane fields (scaled to TC$\mathrm{CON}$ total columns). This is true for the whole altitude range from ground level to the top of the atmosphere and over all ten TCCON stations considered in this study. Moreover, the retrieval results from measurements over the ocean and the nighttime measurements over land, are all consistent with each other. Only at low altitudes, where the measurements have only limited sensitivity, the daytime measurements over land seem to show a persistent positive bias of $\approx 1 \%$ at low altitudes. These scenes generally show a larger contrast between the Earth's skin temperature and the temperature of the lowest atmospheric levels, with respect to ocean scenes or nighttime observations. The reason that the bias correction scheme does not fully account for this bias in methane, may lie in the fact that the HIPPO campaigns are mostly performed over the Pacific, and the daytime land measurements may therefore be under-represented in the data set of residuals to be accounted for in a principal component analysis.

Nevertheless, the average bias in the retrieved GOSATTIR methane profile is less than $2 \%$ over the full altitude range, for all scenes over all TCCON stations, during day and night, when compared with MACC/TCCON values.

Data availability. The GOSAT data on which this research is based can be found through the GOSAT Data Archive Service (GDAS) (GOSAT Data Processing, 2018). For the analysis within this research, methane TCCON data has been used, which can be found through the TCCON Data Archive (TCCON, 2018). In addition, from the MACC repository (ECMWF MACC, 2018) $\mathrm{CH}_{4}$ and $\mathrm{N}_{2} \mathrm{O}$ data have been used. $\mathrm{CO}_{2}$ data is taken from the Carbon Tracker initiative (CarbonTracker, 2018). In the analysis, we have taken meteorological data from ECMWF (ECMWF, 2018). The data in the figures can be downloaded from de Lange and Landgraf (2018).

Competing interests. The authors declare that they have no conflict of interest.

Edited by: John Worden

Reviewed by: Vivienne Payne and one anonymous referee

\section{References}

Bergamaschi, P. and Alexe, M.: Report on the quality of the inverted CH4 fluxes (second report), Tech. Rep. MACC-II Deliverable D_43.4, Tech. Rep., Joint Research Center, European Commission, 2014.

Bergamaschi, P., Frankenberg, C., Meirink, J., Krol, M., Villani, M. G., Houweling, S., Dentener, F., Dlugokencky, E., Miller, J., Gatti, L., Engel, A., and Levin, I.: Inverse modeling of global and regional $\mathrm{CH} 4$ emissions using SCIAMACHY satellite retrievals, J. Geophys. Res., 114, D22301, https://doi.org/10.1029/2009JD012287, 2009.

Borbas, E. and Ruston, B.: The RTTOV UWiremis IR land surface emissivity module, available at: http://nwpsaf.eu/vs_reports/ nwpsaf-mo-vs-042.pdf (last access: 17 April 2018), 2010.

Borbas, E., Knuteson, R., Seemann, S., Weisz, E., Moy, L., and Huang, H.-L.: A high spectral resolution global land surface infrared emissivity database, in: Joint 2007 EUMETSAT Meteorological Satellite Conference and the 15th Satellite Meteorology \& Oceanography Conference of the American Meteorological Society, Amsterdam, the Netherlands, available at: https://www.ssec.wisc.edu/meetings/jointsatmet2007/ pdf/borbas_emissivity_database.pdf (last access: 15 May 2018), 2007.

Borsdorff, T., Hasekamp, O. P., Wassmann, A., and Landgraf, J.: Insights into Tikhonov regularization: application to trace gas column retrieval and the efficient calculation of total column averaging kernels, Atmos. Meas. Tech., 7, 523-535, https://doi.org/10.5194/amt-7-523-2014, 2014.

Bousserez, N., Henze, D., Perkins, A., Bowman, K., Lee, M., Liu, J., Deng, F., and Jones, D.: Improved analysiserror covariance matrix for high-dimensional variational inversions: application to source estimation using a 3D atmospheric transport model, 141, 1906-1921, https://doi.org/10.1002/qj.2495, 2015.

Brenninkmeijer, C. A. M., Crutzen, P., Boumard, F., Dauer, T., Dix, B., Ebinghaus, R., Filippi, D., Fischer, H., Franke, H., Frieß, U., Heintzenberg, J., Helleis, F., Hermann, M., Kock, H. H., Koeppel, C., Lelieveld, J., Leuenberger, M., Martinsson, B. G., Miemczyk, S., Moret, H. P., Nguyen, H. N., Nyfeler, P., Oram, D., O'Sullivan, D., Penkett, S., Platt, U., Pupek, M., Ramonet, M., Randa, B., Reichelt, M., Rhee, T. S., Rohwer, J., Rosenfeld, K., Scharffe, D., Schlager, H., Schumann, U., Slemr, F., Sprung, D., Stock, P., Thaler, R., Valentino, F., van Velthoven, P., Waibel, A., Wandel, A., Waschitschek, K., Wiedensohler, A., Xueref-Remy, I., Zahn, A., Zech, U., and Ziereis, H.: Civil Aircraft for the regular investigation of the atmosphere based on an instrumented container: The new CARIBIC system, Atmos. Chem. Phys., 7, 4953-4976, https://doi.org/10.5194/acp-7-4953-2007, 2007.

Butz, A., Guerlet, S., Hasekamp, O., Schepers, D., Galli, A., Aben, I., Frankenberg, C., Hartmann, J.-M., Tran, H., Kuze, A., Keppel-Aleks, G., Toon, G., Wunch, D., Wennberg, P., Deutscher, N., Griffith, D., Macatangay, R., Messerschmidt, J., Notholt, J., and Warneke, T.: Toward accurate $\mathrm{CO} 2$ and $\mathrm{CH} 4$ observations from GOSAT, Geophys. Res. Lett., 38, L14812, https://doi.org/10.1029/2011GL047888, 2011.

CarbonTracker: CarbonTracker Data, available at: https://www.esrl. noaa.gov/gmd/dv/ftpdata.html, last access: 19 June 2018.

CarbonTracker website: Carbon Tracker, available at: http:// carbontracker.noaa.gov, last access: 15 May 2018. 
Cressot, C., Chevallier, F., Bousquet, P., Crevoisier, C., Dlugokencky, E. J., Fortems-Cheiney, A., Frankenberg, C., Parker, R., Pison, I., Scheepmaker, R. A., Montzka, S. A., Krummel, P. B., Steele, L. P., and Langenfelds, R. L.: On the consistency between global and regional methane emissions inferred from SCIAMACHY, TANSO-FTS, IASI and surface measurements, Atmos. Chem. Phys., 14, 577-592, https://doi.org/10.5194/acp14-577-2014, 2014.

Crevoisier, C., Nobileau, D., Armante, R., Crépeau, L., Machida, T., Sawa, Y., Matsueda, H., Schuck, T., Thonat, T., Pernin, J., Scott, N. A., and Chédin, A.: The 2007-2011 evolution of tropical methane in the mid-troposphere as seen from space by MetOp-A/IASI, Atmos. Chem. Phys., 13, 4279-4289, https://doi.org/10.5194/acp-13-4279-2013, 2013.

Dee, D., Uppala, S., Simmons, A., Berrisford, P., Poli, P., Kobayashi, S., Andrae, U., Balmaseda, M., Balsamo, G., Bauer, P., Bechtold, P., Beljaars, A., van de Berg, L., Bidlot, J., Bormann, N., Delsol, C., Dragani, R., Fuentes, M., Geer, A., Haimberger, L., Healy, S., Hersbach, H., Hólm, E., Isaksen, L., Kållberg, P., M.Köhler, Matricardi, M., McNally, A., MongeSanz, B., Morcrette, J.-J., Park, B.-K., Peubey, C., de Rosnay, P., Tavolato, C., Thépaut, J.-N., and Vitart, F.: The ERAInterim reanalysis: configuration and performance of the data assimilation system, Q. J. Roy. Meteor. Soc., 137, 553-597, https://doi.org/10.1002/qj.828, 2011.

de Lange, A. and Landgraf, J.: Data used in Figures, available at: ftp://ftp.sron.nl/open-access-data/jochen/de_Lange_2018, last access: 19 June 2018.

ECMWF: ECMWF Interim Full Daily Data, available at: http: //apps.ecmwf.int/datasets/data/interim-full-daily/, last access: 19 June 2018.

ECMWF MACC: ECMWF MACC GHG inversions, available at: http://apps.ecmwf.int/datasets/data/macc-ghg-inversions/, last access: 19 June 2018.

GOSAT Data Processing: GOSAT Data Archive Service, available at: https://data2.gosat.nies.go.jp, last access: 19 June 2018.

Han, Y., Revercomb, H., Cromp, M., Gu, D., Johnson, D., Mooney, D., Scott, D., Strow, L., Bingham, G., Borg, L., Chen, Y., DeSlover, D., Esplin, M., Hagan, D., Jin, X., Knuteson, R., Motteler, H., Predina, J., Suwinski, L., Taylor, J., Tobin, D., Tremblay, D., Wang, C., Wang, L., Wang, L., and Zavyalov, V.: Suomi NPP CrIS measurements, sensor data record algorithm, calibration and validation activities, and record data quality, J. Geophys. Res., 118, 12734-12748, https://doi.org/10.1002/2013JD020344, 2013.

Hansen, P.: Analysis of discrete ill posed problems by means of the L-curve, SIAM Rev., 34, 561-580, 1992.

Hasekamp, O. P. and Landgraf, J.: Ozone profile retrieval from backscattered ultraviolet radiances: The inverse problem solved by regularization, J. Geophys. Res., 106, 8077-8088, https://doi.org/10.1029/2000JD900692, 2001.

Holl, G., Walker, K. A., Conway, S., Saitoh, N., Boone, C. D., Strong, K., and Drummond, J. R.: Methane cross-validation between three Fourier transform spectrometers: SCISAT ACEFTS, GOSAT TANSO-FTS, and ground-based FTS measurements in the Canadian high Arctic, Atmos. Meas. Tech., 9, 19611980, https://doi.org/10.5194/amt-9-1961-2016, 2016.

Inoue, M., Morino, I., Uchino, O., Miyamoto, Y., Saeki, T., Yoshida, Y., Yokota, T., Sweeney, C., Tans, P. P., Biraud, S. C., Machida,
T., Pittman, J. V., Kort, E. A., Tanaka, T., Kawakami, S., Sawa, Y., Tsuboi, K., and Matsueda, H.: Validation of $\mathrm{XCH}_{4}$ derived from SWIR spectra of GOSAT TANSO-FTS with aircraft measurement data, Atmos. Meas. Tech., 7, 2987-3005, https://doi.org/10.5194/amt-7-2987-2014, 2014.

Jacob, D. J., Turner, A. J., Maasakkers, J. D., Sheng, J., Sun, K., Liu, X., Chance, K., Aben, I., McKeever, J., and Frankenberg, C.: Satellite observations of atmospheric methane and their value for quantifying methane emissions, Atmos. Chem. Phys., 16, 14371-14396, https://doi.org/10.5194/acp-16-143712016, 2016.

Karion, A., Sweeney, C., Tans, P., and Newberger, T.: AirCore: An Innovative Atmospheric Sampling System, J. Atmos. Ocean. Tech., 27, 1839-1853, https://doi.org/10.1175/2010JTECHA1448.1, 2010.

Kuze, A., Suto, H., Nakajima, M., and Hamazaki, T.: Thermal and near infrared sensor for carbon observation Fouriertransform spectrometer on the Greenhouse Gases Observing Satellite for greenhouse gases monitoring, Appl. Opt., 48, 67166733, https://doi.org/10.1364/AO.48.006716, 2009.

Kuze, A., Taylor, T., Kataoka, F., Bruegge, C., Crisp, D., Harada, M., Helmlinger, M., Inoue, M., Kawakami, S., Kikuchi, N., Mitomi, Y., Murooka, J., Naito, M., D.M. O'Brien, C. O., Ohyama, H., Pollock, H., Schwandner, F., Shiomi, K., Suto, H., Takeda, T., Tanaka, T., Urabe, T., Yokota, T., and Yoshida, Y.: Long term vicarious calibration of GOSAT sensors; techniques for error reduction and new estimates of degradation factors, IEEE T. Geosci. Remote, 52, 3991-4004, https://doi.org/10.1109/TGRS.2013.2278696, 2014.

Kuze, A., Suto, H., Shiomi, K., Kawakami, S., Tanaka, M., Ueda, Y., Deguchi, A., Yoshida, J., Yamamoto, Y., Kataoka, F., Taylor, T. E., and Buijs, H. L.: Update on GOSAT TANSOFTS performance, operations, and data products after more than 6 years in space, Atmos. Meas. Tech., 9, 2445-2461, https://doi.org/10.5194/amt-9-2445-2016, 2016.

Landgraf, J., aan de Brugh, J., Scheepmaker, R., Borsdorff, T., Hu, H., Houweling, S., Butz, A., Aben, I., and Hasekamp, O.: Carbon monoxide total column retrievals from TROPOMI shortwave infrared measurements, Atmos. Meas. Tech., 9, 49554975, https://doi.org/10.5194/amt-9-4955-2016, 2016.

Machida, T., Matsueda, H., Sawa, Y., Nakagawa, Y., Hirotani, K., Kondo, N., Goto, K., Nakazawa, N., Ishikawa, K., and Ogawa, T.: Worldwide measurements of atmospheric $\mathrm{CO} 2$ and other trace gas species using commercial airlines, J. Atmos. Ocean. Tech., 25, 1744-1754, https://doi.org/10.1175/2008JTECHA1082.1, 2008.

Mlawer, E. J., Payne, V. H., Moncet, J.-L., Delamere, J. S., Alvarado, M. J., and Tobin, D. C.: Development and recent evaluation of the MT_CKD model of continuum absorption, Philos. T. R. Soc. Lond., 370, 2520-2556, https://doi.org/10.1098/rsta.2011.0295, 2012.

Myhre, G., Shindell, D., Bréon, F.-M., Collins, W., Fuglestvedt, J., Huang, J., Koch, D., Lamarque, J.-F., Lee, D., Mendoza, B., Nakajima, T., Robock, A., Stephens, G., Takemura, T., and Zhang, H.: Anthropogenic and Natural Radiative Forcing, in: Climate Change 2013: The Physical Science Basis, Contribution of Working Group I to the Fifth Assessment Report of the Intergovernmental Panel on Climate Change, edited by: Stocker, T., Qin, D., Plattner, G.-K., Tignor, M., Allen, S., Boschung, J., 
Nauels, A., Xia, Y., Bex, V., and Midgley, P., Chap. 8, Cambridge University Press, Cambridge, United Kingdom and New York, NY, USA, 2013.

OCO-2: Orbiting Carbon Observatory-2 (OCO-2) Level 2 Full Physics Retrieval Algorithm Theoretical Basis, available at: https://docserver.gesdisc.eosdis.nasa.gov/public/project/ OCO/OCO2_L2_ATBD.V6.pdf (last access: 15 May 2018), 2015

Peters, W., Jacobson, A., Sweeney, C., Andrews, A., an, T. C., Masarie, K., Miller, J., Bruhwiler, L. P., Petron, G., Hirsch, A., Worthy, D. J., van der Werf, G., Randerson, J., Wennberg, P., Krol, M., and Tans., P.: An atmospheric perspective on North American carbon dioxide exchange: CarbonTracker, P. Natl. Acad. Sci. USA, 104, 18925-18930, https://doi.org/10.1073/pnas.0708986104, 2007.

Phillips, P.: A technique for the numerical solution of certain integral equations of the first kind, J. Assoc. Comput. Mach., 9, 84-97, 1962.

Razavi, A., Clerbaux, C., Wespes, C., Clarisse, L., Hurtmans, D., Payan, S., Camy-Peyret, C., and Coheur, P. F.: Characterization of methane retrievals from the IASI space-borne sounder, Atmos. Chem. Phys., 9, 7889-7899, https://doi.org/10.5194/acp-9-78892009, 2009.

Rothman, L., Gordon, I., Barbe, A., Benner, D. C., Bernath, P., Birk, M., Boudon, V., Brown, L., Campargue, A., Champion, J.-P., Chance, K., Coudert, L., Dana, V., Devi, V., Fally, S., Flaud, J.-M., Gamache, R., Goldman, A., Jacquemart, D., Kleiner, I., Lacome, N., Lafferty, W., Mandin, J.-Y., Massie, S., Mikhailenko, S., Miller, C., Moazzen-Ahmadi, N., Naumenko, O., Nikitin, A., Orphal, J., Perevalov, V., Perrin, A., Predoi-Cross, A., Rinsland, C., Rotger, M., Šimečková, M., Smith, M., Sung, K., Tashkun, S., Tennyson, J., Toth, R., Vandaele, A., and Auwera, J. V.: The HITRAN 2008 molecular spectroscopic database, J. Quant. Spectrosc. Ra., 110, 533-572, https://doi.org/10.1016/j.jqsrt.2009.02.013, 2009.

Saitoh, N., Imasu, R., Ota, Y., and Niwa, Y.: CO2 retrieval algorithm for the thermal infrared spectra of the Greenhouse Gases Observing Satellite: Potential of retrieving $\mathrm{CO} 2$ vertical profile from high-resolution FTS sensor, J. Geophys. Res., 114, D17305, https://doi.org/10.1029/2008JD011500, 2009.

Saitoh, N., Touno, M., Hayashida, S., Imasu, R., Shiomi, K., Yokota, T., Yoshida, Y., Machida, T., Matsueda, H., and Sawa, Y.: Comparisons between XCH4 from GOSAT Shortwave and Thermal Infrared Spectra and Aircraft CH4 Measurements over Guam, SOLA, 8, 145-149, https://doi.org/10.2151/sola.2012036, 2012.

Schepers, D., Guerlet, S., Butz, A., Landgraf, J., Frankenberg, C., Hasekamp, O., Blavier, J.-F., Deutscher, N., Griffith, D., Hase, F., Kyro, E., Morino, I., Sherlock, V., Sussmann, R., and Aben, I.: Methane retrievals from Greenhouse Gases Observing Satellite (GOSAT) shortwave infrared measurements: Performance comparison of proxy and physics retrieval algorithms, J. Geophys. Res., 117, D10307, https://doi.org/10.1029/2012JD017549, 2012.

Seemann, S., Borbas, E., Knuteson, R., Stephenson, G., and Huang, H.-L.: Development of a Global Infrared Land Surface Emissivity Database for Application to Clear Sky Sounding Retrievals from Multi-spectral Satellite Radiance
Measurements, J. Appl. Meteorol. Clim., 47, 108-123, https://doi.org/10.1175/2007JAMC1590.1, 2008.

Siddans, R., Knappett, D., Kerridge, B., Waterfall, A., Hurley, J., Latter, B., Boesch, H., and Parker, R.: Global heightresolved methane retrievals from the Infrared Atmospheric Sounding Interferometer (IASI) on MetOp, Atmos. Meas. Tech., 10, 41354164, https://doi.org/10.5194/amt-10-4135-2017, 2017.

Steck, T.: Methods for determining regularization for atmospheric retrieval problems, Appl. Opt., 41, 1788-1797, 2002.

TCCON: TCCON Data, available at: https://tccondata.org/, last access: 19 June 2018.

TCCON Data Description website: Data description, available at: https://tccon-wiki.caltech.edu/Network_Policy/Data_ Use_Policy/Data_Description, last access: 15 May 2018.

Tikhonov, A.: On the solution of incorrectly stated problems and a method of regularization, Dokl. Akad. Nauk SSSR, 151, 501$504,1963$.

Twomey, S.: On the numerical solution of Fredholm integral equations of the first kind by inversion of the linear system produced by quadrature, J. Assoc. Comput. Mach., 10, 97-101, 1963.

van Delst, P. and Wu, X.: A high resolution infrared sea surface emissivity database for satellite applications, in: Technical Proceedings of The Eleventh International ATOVS Study Conference, 407-411, 2000.

von Clarmann, T., Höpfner, M., Kellmann, S., Linden, A., Chauhan, S., Funke, B., Grabowski, U., Glatthor, N., Kiefer, M., Schieferdecker, T., Stiller, G. P., and Versick, S.: Retrieval of temperature, $\mathrm{H}_{2} \mathrm{O}, \mathrm{O}_{3}, \mathrm{HNO}_{3}, \mathrm{CH}_{4}, \mathrm{~N}_{2} \mathrm{O}, \mathrm{ClONO}_{2}$ and $\mathrm{ClO}$ from MIPAS reduced resolution nominal mode limb emission measurements, Atmos. Meas. Tech., 2, 159-175, https://doi.org/10.5194/amt-2159-2009, 2009.

Wassmann, A., Landgraf, J., and Aben, I.: Ozone profiles from clear sky thermal infrared measurements of the Infrared Atmospheric Sounding Interferometer: A retrieval approach accounting for thin cirrus, J. Geophys. Res., 116, D22302, https://doi.org/10.1029/2011JD016066, 2011.

Wecht, K. J., Jacob, D. J., Wofsy, S. C., Kort, E. A., Worden, J. R., Kulawik, S. S., Henze, D. K., Kopacz, M., and Payne, V. H.: Validation of TES methane with HIPPO aircraft observations: implications for inverse modeling of methane sources, Atmos. Chem. Phys., 12, 1823-1832, https://doi.org/10.5194/acp12-1823-2012, 2012.

Worden, J., Kulawik, S., Frankenberg, C., Payne, V., Bowman, K., Cady-Peirara, K., Wecht, K., Lee, J.-E., and Noone, D.: Profiles of $\mathrm{CH}_{4}, \mathrm{HDO}, \mathrm{H}_{2} \mathrm{O}$, and $\mathrm{N}_{2} \mathrm{O}$ with improved lower tropospheric vertical resolution from Aura TES radiances, Atmos. Meas. Tech., 5, 397-411, https://doi.org/10.5194/amt-5397-2012, 2012.

Worden, J. R., Turner, A. J., Bloom, A., Kulawik, S. S., Liu, J., Lee, M., Weidner, R., Bowman, K., Frankenberg, C., Parker, R., and Payne, V. H.: Quantifying lower tropospheric methane concentrations using GOSAT near-IR and TES thermal IR measurements, Atmos. Meas. Tech., 8, 3433-3445, https://doi.org/10.5194/amt-8-3433-2015, 2015.

$\mathrm{Wu}, \mathrm{X}$. and Smith, W.: Emissivity of rough sea surface for $8-13 \mu \mathrm{m}$ : modeling and verification, Appl. Opt., 36, 2609-2619, 1997.

Wunch, D., Toon, G., Blavier, J.-F., Washenfelder, R., Notholt, J., Connor, B., Griffith, D., Sherlock, V., and Wennberg, P.: The To- 
tal Carbon Column Observing Network, Philos. T. R. Soc. A, 369, 2087-2112, https://doi.org/10.1098/rsta.2010.0240, 2011.

Xiong, X., Barnet, C., Maddy, E., Sweeney, C., Liu, X., Zhou, L., and Goldberg, M.: Characterization and validation of methane products from the Atmospheric Infrared Sounder (AIRS), J. Geophys. Res., 113, 2005-2012, 2008.
Zou, M., Xiong, X., Saitoh, N., Warner, J., Zhang, Y., Chen, L., Weng, F., and Fan, M.: Satellite observation of atmospheric methane: intercomparison between AIRS and GOSAT TANSO-FTS retrievals, Atmos. Meas. Tech., 9, 3567-3576, https://doi.org/10.5194/amt-9-3567-2016, 2016. 